Romanov Yu. O., Candidate of Philology, Associate Professor, Associate Professor at the Department of Humanities National Technical University "Kharkiv Polytechnic Institute"

\title{
THE AKTIONSARTEN AS A LACUNA FOR RFL LEARNERS
}

Summary. The article is devoted to a detailed analysis of the Aktionsarten; despite diversity and large volume, they are not covered by existing RFL (Russian as a foreign language) programs.

Semantic and structural types of verbs that demonstrate a change in the meaning of a motivating prefixless verb in terms of expressing temporal, quantitative, and terminative characteristics of an action after adding appropriate affixes to it are considered to be Aktionsarten. Most Aktionsarten are formed from imperfective verbs by adding certain prefixes (and in the case at hand, the postfix - $c я$ ) resulting in Aktionsarten related to the perfective aspect. An insignificant number of Aktionsarten formed with the help of imperfect suffixes $-8 a$ , $-u в(a)-,-b l b(a)$ - refer to the imperfective aspect.

The concept of Aktionsart was introduced by the Swedish linguist S. Agrell to designate the semantic functions of prefixed verbs which clarify the nature of the action; he was the first to distinguish the category of the aspect of a verb from the category of Aktionsart. Further study of the nature of the course of action and aspects expanded the understanding of the term: Aktionsarten are correlated not only with prefix verb formations but also with all verb derivatives formed with the help of other word-formation means (prefixes, suffixes, postfixes, and their combination). This article considers the meaning of semantic and derivational groups of verbs distinguished on the basis of temporal, quantitative, and terminative characteristics. With this approach, the concept of Aktionsart is not applicable to the entire verb vocabulary; this is the case of verbs that are verbal derivatives (their derivational formants are considered to be modification formants).

The article attempts to minimize (for the purposes of RFL teaching) the number of Aktionsarten and provide lists of the most commonly used and semantically transparent verbs with rich word-formation potential; examples of their use in a poetic context are meant to interest students in literary works; the effective learning of Aktionsarten undoubtedly opens new opportunities for international students in RFL acquisition.

Key words: Aktionsarten, verb aspect, word-formation, L2 teaching, Russian as a foreign language, international students.

Problem statement. In the Russian language, the category of the aspect of a verb is a non-inflectional grammatical category. It denotes the relation of an action to an internal limit and is formed by the opposition of verbs with grammatical meanings of a limited action (the perfective) and an unlimited action (the imperfective). In this case, the perfective is a marked member of the aspectual opposition denoting the result of the action (the limit), and the imperfective is its unmarked member denoting the action in progress (the limit is not specified). An aspectual pair is based on the semantic coincidence of its members which differ in the grammatical meaning of limit and non-limit. The marking of verbs of an aspectual pair occurs using formal linguistic means (prefixes, suffixes, alternation of sounds, stresses, suppletion).

In Romano-Germanic languages, the aspectual correlation of Russian verbs (already embedded in the infinitives) corresponds to the perfective forms-meanings and imperfective forms-meanings of verbs. Therefore, in principle, the transfer of this knowledge from the intermediate language to the Russian language doesn't normally cause any catastrophic difficulties for an L2 learner since the number of academic hours for studying the verb aspects in RFL programs is quite enough.

But the category of aspect is closely related to the Aktionsarten not covered by RFL programs despite the fact that they are very extensive, diverse, and require L2 learners to deeply penetrate into them and have a real language instinct.

Semantic and structural types of verbs that demonstrate a change in the meaning of a motivating prefixless verb in terms of expressing temporal, quantitative, and terminative characteristics of an action after adding appropriate affixes to it are considered to be Aktionsarten.

Most Aktionsarten are formed from imperfective verbs by adding certain prefixes (and in the case at hand, the postfix $-c \Omega$ ) resulting in Aktionsarten related to the perfective aspect. An insignificant number of Aktionsarten formed with the help of imperfect suffixes $-в a-,-u в(a)-,-b l b(a)$ - refer to the imperfective aspect.

Particular attention should be paid to the following:

- unlike the aspectual pairs, the Aktionsarten are one-aspect;

- the belonging of Russian verbs to one of the aspects is obvious; the belonging to Aktionsarten is not;

- the coverage of the verbal lexicon by the verb aspect is total; as for Aktionsarten, it is very limited;

- the exact composition of Aktionsarten is uncertain; moreover, the boundaries between Aktionsarten are often blurred.

But ignorance of the essence of Aktionsarten and their verbal content impoverishes the category of aspect; therefore, despite the large number of Aktionsarten, it is necessary to draw students' attention to this semantic-derivational category.

Analysis of recent researches. The concept of Aktionsart was introduced by the Swedish linguist S. Agrell to designate the semantic functions of prefixed verbs which clarify the nature 
of the action ("Aktionsart" (Germ.) - "kind of action" can be also found in the work of Karl Brugmann (1885), or even earlier). S. Agrell was the first to distinguish the category of the aspect of a verb from the category of Aktionsart [1].

Further study of the nature of the course of action and aspects expanded the understanding of the term: Aktionsarten are correlated not only with prefix verb formations but also with all verb derivatives formed with the help of other word-formation means (prefixes, suffixes, postfixes, and their combination) [2-3]. For example, A.V. Bondarko distinguishes "characterized" Aktionsarten which differ in a certain formal feature and are word-formative categories, "uncharacterized" Aktionsarten that do not have the indicated feature, and "inconsistently characterized" Aktionsarten [4].

Due to the fact that the methods of verbal action are applicable only to the groups of verbs in which the modification occurs with the help of a word-formative formant, different interpretations of Aktionsarten appear in science. In particular, A.V. Isachenko points out the aspectual "inconsistency" of Aktionsarten and distinguishes between the "accomplishments" and "character" of Aktionsarten [5].

N.S. Avilova opposed the classification of A.V. Bondarko and singled out the temporal, quantitative and speciallyproductive Aktionsarten. In her opinion, the formal expression of the modification of the original meaning is obligatory for expressing one or another Aktionsart [6].

According to I. Pálosi, the category of Aktionsart is a semanticword formation category, one that includes motivated verbs with formal markers of semantic change of the base verb, except for verbs of motion [7].

In this work, we consider the meaning of semantic and derivational groups of verbs distinguished on the basis of temporal, quantitative, and terminative characteristics. With this approach, the concept of Aktionsart is not applicable to the entire verb vocabulary; this is the case of verbs that are verbal derivatives (their derivational formants are considered to be modification formants) [8].

The purpose of the study is to provide guidance on how to minimize (for the needs of RFL teaching) the number of Aktionsarten and to select the most obvious terminologically and semantically transparent Aktionsarten, as well as frequent Aktionsarten whose word-formative potential is rich and productive. Minimization of Aktionsarten, the presented lists of verbs, as well as examples of their use in the poetic context are to help facilitate students' psychological overcoming on their way to new knowledge.

Presentation main material. We describe the semantics of Aktionsarten and their word formation means.

Perfective verbs:

- inceptive $(3 a-; 3 a-\ldots-c я ;$ no-; no-...-cя) and intensiveinceptive Aktionsarten (83-/вc-; 8з-/вc-...-ся; воз-/вос-; воз-/вос-... -ся; раз-/рас-...-ся): express the meaning of beginning of an action, or intensive beginning of an action: запеть, засмеяться; подуть, помчаться; взреветь, взмолиться; вскрикнуть, возненавидеть, воспламениться; размечтаться, расплакаться;

- finitive Aktionsart ( $\partial-;$ om-; om-...-ca): expresses the meaning of termination of a continuous action: doчumamb; отивести, отвоеваться;

- restrictive Aktionsart (no-; no...-ca): expresses the meaning of limiting action in time; continuous-restrictive Aktionsart: expresses the meaning of a continuous limitation of an action in time (про-): поплакать, поульбаться; проплакать (весь вечер);
- cumulative Aktionsart ( $(\mathrm{a}-$ )): expresses the meaning of accumulating; saturative Aktionsart ( $\mathrm{Ha}-\mathrm{-..-C}-\mathrm{c})$ expresses the meaning of oversaturation of the subject with an action: накупить (овощей); нарвать (цветов); наиграться, насмотреться;

- diminutive Aktionsart (вз-/вc-; вз-/вC-...-ся; no-; no-... -ся; под-; под-...-ся; при-; при-...-ся): expresses the meaning of an incomplete action: всплакнуть, взгрустнуться, поотстать, поизноситься, подучить, подкраситься, приболеть, приподняться;

- distributive-summary (total) Aktionsart (uз- uc-; no-; nepe-): expresses the meaning of total coverage of the object by an action: изрисовать, исписать (всю тетрадь), позакрывать (все окна), перебить (всю посуду);

- intensive Aktionsart ( 6 -...-cя; pa3-/pac-): expresses the meaning of deepening in an action, and intensity: вчитаться, въесться, расиеловать, разругать;

- continuous-intensive Aktionsart (uз-; uc-; uз-; uc-...-cя): expresses the meaning of completeness and intensity of an action with negative psycho-physical effects for the subject: измучить, иссушить, измучиться, исстрадаться;

- terminative-intensive Aktionsart (3a-...-ca): expresses the meaning of extreme completeness, and an intensive action: заиграться, замучиться;

- intensive-terminative Aktionsart (bbl-; вbl-...-cя; uз-/uc-; из-/ис-...-ся; от-; пере-; пере-...-ся; про-; про-...-ся): expresses the meaning of completeness and exhaustion of the result: выстрадать, вылечиться; изжарить, износиться, испугаться; отгладить, перетрусить, переволноваться; проварить, проголодаться;

- continuous-terminative Aktionsart (до-...-ся; nepe-; nepe-...-cя; $y$-...-cя): expresses the meaning of performance over time, as well as a negative effect for the subject: дозвониться, допрыгаться; перегреть, переутомиться; убе́гаться;

- terminative Aktionsart $(B-; \quad B-\ldots-c я ; \quad B 3-/ B C-; \quad B 3-/ B C-\ldots$ -ся; вbl-; вbl-..-ся; до-...-ся; за-; за-..-ся; на-; $н а-\ldots-с я ;$ от-; от-...-ся; nо-; по-...-ся; при-; при-..-ся; про-; $y$-; $y-\ldots-c a)$ : expresses different meanings of the result of an action: a) moving: up (вскинуть, вспорхнуть, вскарабкаться); inward (влить, влиться); from the inside (вылить, вылиться); covering the surface (наклеить, заклеить, забрызгаться); removing (отклеить, отклеиться); approaching (подсесть); joining (приклеить, приклеиться); from below (подставить); down (спрыгнуть, спуститься); through (проколоть); to the center (сдвинуть, сблизиться); from the center (раздвинуть, расползтись); displacement (переселить, переселиться); b) actual result (взбесить, вскормить, воздержаться; затвердеть, засориться; нагреть, нагреться; построить, попрощаться; приучить, приучиться; прожить; убаюкать, умытться); с) response (отблагодарить); d) evasive response (отписаться, отиутиться); e) inadvertent discovery (проговориться, проболтаться);

- terminative Aktionsart between several participants (no-... -ся; раз-/рас-...-ся; с-...-ся; $у$-...-ся): подраться, расиеловаться, созвониться, увидеться.

Imperfective verbs (Aktionsarten expressed by prefixes, imperfect suffixes, and postfix -cr):

- continuous-diminutive Aktionsart ( $\mathrm{Ha}$-): expresses the meaning of a continuous and incomplete action: напевать, насвистывать; 
- intermittent-diminutive Aktionsart (no-): expresses the actions repeated from time to time: покрикивать, покашливать;

- continuous-intensive Aktionsart between several participants (nepe-...-cr): expresses the meaning of completeness and intensity of an action: переписываться, перезваниваться;

- accompanying Aktionsart (nod-; npu-): express the meaning of accompanying another action: подпевать, припевать.

We describe word-building formants of verbs and their semantic register.

Prefix $6-;$ prefix 6 - and postfix -cя:

- intensive Aktionsart with the meaning of deepening in an action: вдуматься, вслушаться, всмотреться, вчитаться, вжчться, вглядеться, въесться;

- terminative Aktionsart with the meaning of moving inward: влить, вбросить, втолкнуть, вложить, вписать, воткнуть, вставить, ввинтить, вклеить; впиться. Сf.: Сколько пуль в наши спины вцарапали (Есенин); Вгрызлись в букву едящие глаза (Маяковский).

Prefixes $63-/ 8 c-;$ воз-/воc-; prefixes $63-/ B c$ - and postfix -cя; prefixes $603-/ 80 c$ - and postfix -cя:

- intensive-inceptive Aktionsart: взреветь, взвыть, взвизгнуть, возомнить, возлюбить, воспылать, вскрикнуть, встревожить, взволновать, возненавидеть; взволноваться, возрадоваться, воспламениться, возгореться, возгордиться, взмолиться, возродиться, взбелениться, вздуриться, встревожиться. Сf.: Медведь взревел и замертво упал (Крылов); Из искры возгорится пламя (Пушкин);

- diminutive Aktionsart: всплакнуть, вздремнуть, взгрустнуть; встрепенуться, вспомниться, взгрустнуться; Пускай тебе взгрустнется даже, / Tbl головы не опускай! (Лебедев-Кумач);

- terminative Aktionsart: вскипеть, вспахать, взбесить, взволновать, возразить, вскормить, вспотеть, вскружить (голову), возмужать; воспротивиться, воздержаться; Уходят люди... / Их не возвратить. / И тайные миры не возродить (Евтушенко); a number of verbs have the additional meaning of moving up: вскинуть, взметнуть, вздернуть, вспорхнуть, воспарить, возвести (многоэтажку); вскарабкаться, взвиться; И пусть над нашим смертныл ложем / Взовьется с криком воронье (Блок).

Prefix $6 b l-;$ prefix $b b l$ - and postfix $-c a$ :

- intensive-terminative Aktionsart: выстирать, выстрадать, выплакать, выварить, выпечь, выгулять, выкопать, выучить, вылечить, высушить, вызреть, выкрасить, вылизать, вылокнуть, выстроить, вызубрить; вылежаться, выспаться, выплакаться, выгуляться, выучиться, вылечиться, выпрямиться, выговориться. Сf.: Эти рысьи твои глаза, Азия, / Что-то высмотрели во мне, / Что-то вылразнили подспудное (Ахматова); Что за чудо? Видно, выспался он [пес] худо (Пушкин);

- terminative Aktionsart with the meaning of moving from the inside: вылить, вытряхнуть, высунуть, выкатить, выплюнуть, вышвырнуть, выбросить, вытащить, вынырнуть, выпрыгнуть, вытолкнуть; выбраться, вылиться, выброситься, вытряхнуться, выкатиться, высунуться, вылупиться, выкарабкаться, выбиться (в люди). Сf.: Братья дружною толпою / Выезжают погулять... / Или вытравить из леса / Пятигорского черкеса (Пушкин); Убьёте, похороните - / выроюсь (Маяковский).
Prefix $\partial о$-; prefix $\partial о$ - and postfix -cя:

- finitive Aktionsart: доварить, доделать, дописать, дочитать, допеть, догулять, договорить, дорисовать, додумать, дожарить, докурить, дожить, дошить; то, что отиь не допели, - / мы допоем! (Рождественский); a number of verbs have the meaning of a complementary action: доплатить, докупить, долить, дополучить, дослать, досыпать, доработать;

- continuous-terminative Aktionsart: дозвониться, докричаться, достучаться, добудиться, досидеться, дождаться, допроситься; a number of verbs have the meaning of a negative effect for the subject: допрыгаться, допеться, доплясаться, доиграться, дописаться, дочитаться, дошутиться, догуляться, дотанцеваться, доотдыхаться; Так! вам одним лишь удалось / Дойти до нас с брегов другого света. / О, если б про него хоть на один вопрос / Мог допроситься я ответа (Тютчев);

- terminative Aktionsart: домчаться, докопаться, дорыться, дорваться; Пусть ночь. Домчимся. Озарим кострами / Степную даль (Блок).

Prefix $3 a-$; prefix $3 a$ - and postfix -cя:

- inceptive Aktionsart: закричать, заорать, запеть, зарыдать, заплакать, завизжать, зареветь, зашептать, зацвести, заговорить, зашуметь; зашевелиться, засветиться, засмеяться, заволноваться, заульгбаться, засомневаться, забеспокоиться. Сf.: Дом ичаревна обошла, ... / Засветила богу свечку, / Затопила жарко печку (Пушкин); И только небо засветилось, / Все шумно вдруг зашевелилось (Лермонтов);

- terminative Aktionsart: завоевать, заработать, задумать, закончить, загримировать, загнать, зажилить, затуркать, заслать, замучить, загонять, затвердеть, загрубеть, залечить, загнить, засветить, зарегистрировать; закончиться, задуматься, засориться, загримироваться, замаскироваться, заручиться (поддержкой). Сf.: Сердиа жаркого не залить вином, / Думу черную не запотчевать! (Лермонтов); Мешок завеличался, / Заумничал, зазнался. (Крылов); a number of verbs have the meaning of covering by an action: засеять, забрызгать, заклеить, запудрить, замазать, застелить, застроить, заасфальтировать, закрасить, зачеркнуть, залить, заштукатурить; замазаться, забрызгаться, застроиться;

- terminative-intensive Aktionsart: заболтаться, заработаться, заслушаться, засидеться, засмотреться, зачграться, заждаться, загуляться, заучиться, заговориться, замучиться; Гребень затерялся. / Зарезвился мой мальчик, заигрался (Крылов).

Prefixes $и з-/ u c-$; prefixes $и з-/ u c$ - and postfix -ся:

- continuous-intensive Aktionsart with the meaning of a negative effect for the subject: иссохнуть, иссушить, иззябнуть, измучить, издергать; измучиться, истосковаться, исстрадаться. Cf.: Вас молниею заживо / испепелял талант. (Вознесенский); Сердие темное измаялось (Ахматова);

- intensive-terminative Aktionsart: излечить, изувечить, искупить, изуродовать, испугать, испортить, изжарить, износить; излечиться, испугаться, испортиться, изловчиться, износиться. Cf:: За то, что не испортили / Ни песню мы, ни стих, / Давайте выпьем (Слуцкий); Сила молодая / С телом износилась. (Кольцов);

- distributive-summary (total) Aktionsart: избить, искусать, изрезать, исписать, изрубить, изрисовать, изранить, 
изжевать, издырявить, избороздить; Там тело всякого мужчины / исчеркали / война / и труд (Слуцкий).

Prefix нa-; prefix $н \mathrm{Ha}$ - and postfix -ся:

- saturative Aktionsart: наговориться, наесться, напиться, наработаться, наигратся, насидеться, наслушаться, насмотреться, накричаться, налюбоваться, навоеваться, наплясаться, набегаться, натанщеваться, настрадаться, натерпеться; Желая светлым днем вполне налюбоваться, / Орел поднебесью летал (Крылов);

- cumulative Aktionsart: наварить, нарубить, наговорить, накупить, насорить, надылмть, накрошить, настрелять, набрать, настроить, накидать, наловить, насобирать, нарезать, напечь, нарвать, насуиить;

- terminative Aktionsart: нагреть, напугать, намочить, насмешить, нашептать; научиться, наткнуться, нагреться. Cf.: Опять старуха-ревность нашептала / Черт знает что рассудку моему (Щипачев); Я научилась просто, мудро жить (Ахматова); a number of verbs have the meaning of covering the surface: наклеить, напудрить, нацарапать, набросить, накинуть, нахльнуть, налепить, нашить; Он счастлив, если ей накинет / Боа пушистый на плечо (Пушкин);

- continuous-diminutive Aktionsart (with imperfective suffixes): напевать, насвистывать, наигрывать, намептывать, накрапьвать, нахлестыввать (коня).

Prefix om-; prefix om- and postfix -cя:

- finitive Aktionsart: отивести, отгреметь, отобедать, отслужить, отговорить, отзвучать, отшуметь, отгрустить, отболеть, отлюбить; отлучиться, отлежаться, отбегаться, отдылшаться, отмечтаться, отвоеваться. Cf.: с ним [с другом] ушла моя частища - / Отбыла, отпела, отцввела (Грибачев); Не буди того, что отмечталось (Есенин);

- terminative Aktionsart: a number of verbs have the meaning of: a) response (отблагодарить, отреагировать, отдарить; откликнуться, отозваться; Печальная мьсль отзовется / Во глуби бессчетных умов (Брюсов)); b) evasive response (отписаться, отговориться, отмутиться, отмолчаться, отречься); a number of verbs have the meaning of removal, cutting off part (отклеить, отвязать, откатить, отломать, отковырять, отпилить, отбросить, оттолкнуть, отскочить, отсесть; оттолкнуться, отгородиться, откатиться, отклеиться, отломаться; [Первый взвод] погрузился, оттолкнулся / И пошел (Твардовский));

- intensive-terminative Aktionsart: omcmpoumb, отрепетировать, отделать, отгладить, отработать, отрегулировать; отчитаться.

Prefix nepe-; prefix nepe- and postfix -cя:

- intensive Aktionsart between several participants: перессориться, переругаться, перемолвиться, перецеловаться; Вот иарица, наряжаясь / Перед зеркальцем своим, / Перемолвилася с ним (Пушкин);

- continuous-intensive Aktionsart (with imperfective suffixes) between several participants: переписьваться, пересматриваться, перекрикиваться, перешептьваться, перезваниваться, перестреливаться; поздно вечером с лягушками / Перекликаться любит выпь (Гумилев);

- intensive-terminative Aktionsart: переболеть, переосмыслить, перехотеть, перепугать, пережить, перетрусить, перехворать; переволноваться, переутомиться, переполниться. Сf.: Попробуй сам себя восстанови! /
Переболела плоть, перелюбила (Евтушенко); И сам, покорный общему закону, / Переменился я (Пушкин);

- terminative Aktionsart: a number of verbs have the meaning of displacement: переселить, переправить, перекатить, пересесть, перелечь, перетащить, переночевать, перебросить, переставить, пересадить; переселиться, перебраться, переправиться; Лягушка на гору весной / Переселилась (Крылов);

- continuous-terminative Aktionsart: nерегреть, переработать, пережарить, переплатить, переутомить; перезаниматься, переутомиться;

- distributive-summary (total) Aktionsart: перекусать, перебить (всю посуду), переворошить (все вещи), перессорить (всех друзей), переломать (все), переиеловать (всех родных), перестрелять (всех уток), переловить (всех бабочек), переженить (всех внуков).

Prefix no-; prefix no- and postfix -ся:

- inceptive Aktionsart: nодуть, повеять, погнать, потащить, почувствовать; погнаться, помчаться, посыпаться. Сf.: Как поздней осени порою / Бывают дни, бывает час, / Когда повеет вдруг весною (Тютчев); $M$ мb помчимся к бездорожью / В несказанный свет (Блок);

- terminative Aktionsart: поблагодарить, построить, пообедать, помыть, подарить, поссорить, посеять, пожалеть; пожаловаться, поздороваться, попроматься. Сf.: [Земля] Ть дала мне вершину и бездну, / подарила свою широту (Смеляков); Вчера... / Ты поздним позабылась сном (Тютчев);

- terminative Aktionsart between several participants: почеловаться, породниться, пожениться, пообниматься, поругаться, подраться, поссориться, пошептаться; Вот и я выхожу из дома / Повстречаться с иной судьбой, / Цельй мир, чужсой и знакомый / Породниться готов со мной (Гумилев);

- restrictive Aktionsart: посидеть, попрыгать, погулять, поболтать, полежать, поспать, поучить, пописать, порисовать, поработать, погрустить, помечтать, поплакать, nопить, попеть, поесть, покурить, поговорить; поохотиться, посмеяться, поульгбаться, помучаться; Хочешь - давай посмеемся, поплачем! / Хочешь - давай пошумим, помолчим (Алигер);

- diminutive Aktionsart: noomcmamb, попривыкнуть, пообсохнуть, попридержать; поостеречься, поизноситься, поосмотреться; Поросла-убралась ты травой-ковылем. / Да песками ты, степь, позасыпалась (Суриков);

- intermittent-diminutive Aktionsart (with imperfective suffixes): покрикивать, похаживать, посвистывать, поглядывать, покашливать, побаливать, покальвать, поигрывать, позвякивать, покачивать, подумыввать, помалкивать; Ни один боеи и не тронулся, / Лишь стоят да друг друга поталкивают (Лермонтов);

- distributive-summary (total) Aktionsart: позакрывать, пораскидывать, повскакивать, понабирать, повыгонять, nonádamb, noтоптать, посажать.

Prefix noд-; prefix nod- and postfix -cя:

- diminutive Aktionsart: подрасти, подсесть, подпилить, подрисовать, подзакусить, подгримировать, подпудрить, подкрасить, подбелить, подучить, подиутить, подзабыть, подколоть, подработать; подкраситься, подбодриться, подзабыться, подпудриться, подгримироваться; Подстрелили чистенько. / Я уже готов (Евтушенко); 
- terminative Aktionsart with the meaning of: a) moving from below (подставить, подсунуть, подстелить, поднырнуть, подложить, подчеркнуть, подшить); b) approaching (подкатить, подсесть, подтащчить, пододвинуть);

- accompanying Aktionsart (with imperfective suffixes): подпевать, подмигивать, подпрыгивать, поддакивать, подвывать, подсвистывать, подзуживать; И ияарица хохотать, / И плечами пожимать, / И подмигивать глазами (Пушкин).

Prefix $n p u$-; prefix $n p u$ - and postfix -cя:

- diminutive Aktionsart: приболеть, привстать, припомнить, прикусить, притормозить, прилечь, присесть, припугнуть, приоткрыть, приврать, приуныть, прихворнуть, прикорнуть, пристылить; прислушаться, присмотреться, принюхаться, призадуматься, приподняться, прищуриться, принарядиться. Сf.: хуже, коль «полюбишь» по расчету / И на сердие приголубишь ложь (Друнина); [Взвод] пошел. Второй за ним. / Приготовился, пригнулся / Третий следом за вторым (Твардовский);

- terminative Aktionsart: приучить, приготовить, приговорить; приготовиться, причесаться, приспособиться, приесться, приучиться, присниться, притерпеться; Приедается все / Лишь тебе не дано примелькаться (Пастернак); a number of verbs have the meaning of joining: прижать, приклеить, пристроить, прилепить, припарковать; привязаться, приклеиться, припарковаться, прикоснуться, примоститься, прижаться;

- accompanying Aktionsart (with imperfective suffixes): прихрамывать, припевать, приговаривать, присвистьвать, пританцовывать, приплясывать, притопьвать, прихлопывать; И ичарищза хохотать / И прищелкивать перстами, / Гордо в зеркальце глядясь (Пушкин).

Prefix nро-; prefix про- and postfix -ся:

- intensive-terminative Aktionsart: просушить, проварить, прожсарить, пропить, прокутить, промыть, прокипятить, продумать, прорасти; проспаться, продышаться, прокашляться, протрезвиться, прогуляться, пробиться, прослезиться, проголодаться, пробраться, прочихаться; Но чувствовал я в этой книге силу / и знал: ей суждено себя спасти, / прорваться, продолбиться, прорасти (Евтушенко);

- terminative Aktionsart: прозевать, прошипеть, проворонить, пронюхать, промолвить, прозвенеть, пропеть, nропесочить, прожить; a number of verbs have the meaning of inadvertent discovery: проговориться, проболтаться, провороваться; a number of verbs have the meaning of moving through: прогореть, прожечь, продавить, просверлить, проломить, прорезать, прорубить, пробить, прогрызть, проколоть, проковырять, проткнуть. Сf.: Без ошибок не прожить на свете (Друнина); Он из любви со мною проболтался (Пушкин); В Европу прорубил окно (Пушкин);

- continuous-restrictive Aktionsart: проплакать, проговорить, просидеть, проработать (весь день), проболеть, проспать (долго), проискать, прождать, продежурить, простоять, проспорить (весь вечер); Целую ночь проревели ребятушки (Некрасов).

Prefixes раз-/pac-; prefixes раз-/pac- and postfix -ся:

- intensive-inceptive Aktionsart: разволноваться, рассмеяться, расшутиться, расхохотаться, расплакаться, раскричаться, разгореться, расшалиться, раскашляться, размечтаться, расхрабриться, рассердиться; Раззудись плечо! / Размахнись, рука! (Кольцов);

- intensive Aktionsart: расхвалить, расиеловать, рассердить, растревожить, раскормить, развеселить, разругать, разузнать, разглядеть;

- terminative Aktionsart with the meaning of moving from the center: разбросать, развеять, разослать, раскормить, размазать, раздробить, растрезвонить, разорвать; расступиться, разбрестись, разрастись, раздуться, растянуться, расползтись, растечься; Заря алая подымается; / Разметала кудри золотистыле (Лермонтов); Уж зачем ты, алая заря, просыпалася? / На какой ты радости разыгралася? (Лермонтов);

- terminative Aktionsart between several participants: расиеловаться, разговориться, разминуться.

Prefix $c$-; prefix $c$ - and postfix -cя:

- terminative Aktionsart with the meaning of: a) moving down (спрыгнуть, слезть, сползти, слить, стечь; спуститься, скатиться); b) moving to the center (соединить, склеить, согнать, созвать, сдвинуть, столкнуть; сблизиться, слипнуться, слежаться, скорчиться, стечься). Сf.: Не бедствий и сражений годы согнуть и сгорбить не смогли (Слуцкий); Ночь Аль-Кадра. Сошлись, слились вериины / По темным горным склонам / Еще спускаются, слоятся облака (Бунин);

- terminative Aktionsart between several participants: созвониться, списаться, сговориться, спеться, сродниться, сработаться; Горизонтов сомкнулись объятья (Белый).

Prefix $y$-; prefix $y$ - and postfix -cя:

- terminative Aktionsart: укомплектовать, устроить, устранить, убаюкать, ужалить, умьтьь, урегулировать, утаить, усовершенствовать; умыться, ухитриться, улетучиться, умаяться, убраться, укатиться. Сf.: В миг по речи же [братья] спознали, / Что иаревну принимали; / Усадили в уголок, / Подносили пирожок (Пушкин); Женихи ей поклонились, / Потихоньку удалились (Пушкин);

- terminative Aktionsart between several participants: увидеться, уговориться, ужиться; Так мне с гостьми не мудрено ужиться (Крылов);

- continuous-terminative Aktionsart: убе́zаться, укачаться, умориться, уходиться, умаяться, упариться; «Ть утомилась?»-/я говорю. / Она отвечает: «Нет!» (Луговской).

Conclusions.

1) Understanding word-formation potencies of the Russian language (closely connected, in the case at hand, with verb semantics and structure) will help L2 learners not only expand their vocabulary but also develop their ability to perceive new derivatives.

2) Few verbs of the Aktionsarten considered are capable of forming (with the help of secondary imperfectivation) an aspectual pair: inceptive (зацвести - зацветать, вскрикнуть - вскрикивать); finitive (отивести - отиветать); continuous-restrictive (просидеть - просиживать); diminutive (подрасти - подрастать, привстать - привставать). But such formations are irregular, few in number, and besides, newly formed imperfectives can be referred to other Aktionsart. The rest of Aktionsarten are generally inconsistent in aspect.

3) Most Aktionsarten (inceptive, intensive-inceptive, finitive, restrictive, diminutive, intensive, continuous-intensive, terminative, continuous-terminative, intensive-terminative) include both nonreflexive and reflexive verbs; Aktionsarten including predominantly 
only non-reflexive verbs: cumulative, distributive-summary (total), continuous-diminutive, intermittent-diminutive, accompanying; Aktionsarten including only reflexive verbs: saturative, terminativeintensive, continuous-terminative, terminative between several participants, continuous-intensive between several participants.

4) A clearly observed tendency towards more nonreflexive verbs in Aktionsarten is associated with the peculiarity of the meanings of the reflexive verbs themselves.

5) Effective learning of Aktionsarten will undoubtedly open new horizons in the study of the Russian language, let L2 learners adequately perceive and correctly produce discourse, and help attract their interest to literary works.

\section{References:}

1. Agrell S. Aspektänderung und Aktionsartbildung beim polnischen Zeitworte. Lund : Lunds universitets arsskrift, 1908. $157 \mathrm{~s}$.

2. Бондарко А.В. Вид и время русского глагола (значение и употребление) : пособие для студентов. Москва : Просвещение, 1971. 239 с.

3. Маслов Ю.С. Избранные труды: Аспектология. Общее языкознание. Москва : Языки славянской культуры, 2004. 840 с.

4. Бондарко А.В., Буланин Л.В. Русский глагол : пособие для студентов и учителей. Ленинград : Просвещение, 1967. 190 с.

5. Исаченко А.В. Грамматический строй русского языка в сопоставлении со словацким : морфология. Ч. 2. Братислава : изд-во Словацкой Академии наук, $1960.570 \mathrm{c}$.

6. Авилова Н.С. Вид глагола и семантика глагольного слова. Москва : Наука, 1976. 288 c.

7. Палоши И. К основным вопросам о категории способа глагольного действия в русском языке. Slověne. International Journal of Slavic Studies. 2014. Vol. 3. No. 2. P. 194-208.

8. Нагайцева Н.И. Видовременные значения и словоизменение глаголов. Способы глагольного действия : учебно-методическое пособие. Харьков : НТУ «ХПИ», 2019. 72 с.

Нагайцева Н. І., Романов Ю. О. Способи дісслівної дії як лакуна для тих, хто вивчас російську мову як іноземну

Анотація. Статтю присвячено детальному аналізу способів дієслівної дії; незважаючи на розмаїття і великий обсяг, їх вивчення не передбачено наявними програмами з російської як іноземної (РЯІ).

Способами дієслівної дії (СДД) вважають семантико-структурні типи дієслів, які демонструють зміну значення мотивуючого безпрефіксного дієслова після додавання до нього відповідних афіксів щодо вираження часових, кількісних та результативних характеристик дії. Більшість СДД утворюється від дієслів недоконаного виду шляхом додавання певних префіксів (а в нашому випадку і постфікса -ся), в результаті чого з'являються СДД, що належать до доконаного виду. Незначну кількість СДД, що утворюються за допомогою імперфективних суфіксів -ва-, -ив(a)-, -ыв (a)-, відносять до недоконаного виду.

Поняття СДД використовував шведський лінгвіст С. Агрелль для позначення семантичних функцій префіксованих дієслів, які уточнюють характер дії; він першим відділив категорію виду дієслова від категорії СДД. Подальше вивчення природи СДД та виду дієслова розширило розуміння цього терміна: СДД співвідносять не лише 3 префіксальними дієслівними утвореннями, але й $з$ усіма дієслівними похідними, утвореними за допомогою інших словотворчих засобів (префіксів, суфіксів, постфіксів та їх поєднання). У статті розглянуто значення семантичних та дериваційних груп дієслів, що вирізняються за часовими, кількісними та результативними характеристиками. За такого підходу поняття СДД не застосовується до всієї дієслівної лексики; воно включає дієслова, що є дієслівними похідними (їх дериваційні форманти вважаються модифікаційними формантами).

У статті зроблено спробу мінімізувати (для потреб викладання РЯІ) кількість СДД та надати списки найбільш уживаних та семантично прозорих дієслів із багатим словотворчим потенціалом; приклади їх використання в поетичному контексті мають зацікавити студентів літературними творами; ефективне засвоєння СДД, безсумнівно, відкриває нові можливості для студентів-іноземців у вивченні РЯІ.

Ключові слова: способи дієслівної дії, вид дієслова, словотворення, викладання другої мови, російська мова як іноземна, іноземні студенти. 